Article

\title{
Postoperative Neutrophil to Lymphocyte Ratio as an Overall Mortality Midterm Prognostic Factor following OPCAB Procedures
}

\author{
Tomasz Urbanowicz ${ }^{1, *(\mathbb{D})}$, Michał Michalak ${ }^{2}$, Aleksandra Gąsecka ${ }^{3}$, Bartłomiej Perek $^{1}{ }^{1}$, Michał Rodzki $^{1}$, \\ Michał Bociański ${ }^{1}$, Ewa Straburzyńska-Migaj ${ }^{4}$ and Marek Jemielity ${ }^{1}$ \\ 1 Department of Cardiac Surgery and Transplantology, Poznan University of Medical Sciences, \\ 61-848 Poznan, Poland; bperek@ump.edu.pl (B.P.); michal.rodzki@skpp.edu.pl (M.R.); \\ michal.bocianski@skpp.edu.pl (M.B.); mjemielity@poczta.onet.pl (M.J.) \\ 2 Department of Computer Science and Statistics, Poznan University of Medical Sciences, \\ 60-806 Poznan, Poland; michal@ump.edu.pl \\ 3 Department of Cardiology Medical University of Warsaw, 02-091 Warsaw, Poland; gaseckaa@gmail.com \\ 4 Ist Department of Cardiology, Poznan University of Medical Sciences, 61-848 Poznan, Poland; \\ ewa.straburzynska-migaj@skpp.edu.pl \\ * Correspondence: tomasz.urbanowicz@skpp.edu.pl; Tel.: +48-61-854-9210
}

Citation: Urbanowicz, T.; Michalak, M.; Gąsecka, A.; Perek, B.; Rodzki, M.; Bociański, M.; Straburzyńska-Migaj, E.; Jemielity, M. Postoperative Neutrophil to Lymphocyte Ratio as an Overall Mortality Midterm Prognostic Factor following OPCAB Procedures Clin. Pract. 2021, 11, 587-597. https: / / doi.org/10.3390/ clinpract11030074

Received: 12 August 2021

Accepted: 31 August 2021

Published: 3 September 2021

Publisher's Note: MDPI stays neutral with regard to jurisdictional claims in published maps and institutional affiliations.

Copyright: (C) 2021 by the authors. Licensee MDPI, Basel, Switzerland. This article is an open access article distributed under the terms and conditions of the Creative Commons Attribution (CC BY) license (https:/ / creativecommons.org/licenses/by/ $4.0 /)$.

\begin{abstract}
Background: Off-pump coronary artery bypass grafting (OPCAB) is believed to limit inflammatory reaction. Neutrophil to lymphocyte ratio (NLR) is one of the more common and easily accessible markers of inflammatory response. The aim of the study was to compare postoperative results of NLR with mid-term OPCAB results. Methods: In total, 224 patients (198 (88\%) men and $26(12 \%)$ women) with mean age $65+/-9$ years who underwent OPCAB though median full sternotomy in our department in 2018 enrolled into the study. We scrupulously collected the postoperative mid-term results, including survival rate, clinical status and risk for major adverse events, and compared them with perioperative laboratory results. Results: A three-year follow-up was completed by 198 individuals (90\% survival rate) with 12 (5\%) showing major adverse cardiovascular (MACE) events risk. In the multivariable analysis, the laboratory parameters noticed on the 1st postoperative day were statistically significantly predictive of survival, including neutrophils (HR 1.59, 1.33-1.89 95\%CI, $p<0.0001$ ), platelets (HR 1.01, 1.01-1.01 95\%CI, $p=0.0065)$, NLR (HR 1.47, 1.3-1.65 95\%CI, $p<0.0001$ ) and postoperative ejection fraction (HR 0.9, 0.87-0.95 95\%CI, $p<0.0001$ ). Conclusions: Postoperative NLR above 4.6, as an inflammatory reaction marker, is related to mid-term mortality in OPCAB patients.
\end{abstract}

Keywords: NLR 1; OPCAB 2; platelets 3; LVEF 4

\section{Introduction}

The surgical revascularization of coronary artery disease can be performed with cardiopulomnary bypass, or with the "beating heart" technique called off-pump coronary artery bypass grafting (OPCAB). It allows one to omit the cardiopulmonary circuit, along with all possible side effects, including inflammatory reaction activation [1].

Off-pump surgical revascularization of complex coronary artery disease has gained worldwide attention [2-4]. The major advantage of off-pump coronary artery bypass grafting (OPCAB) consists in the avoidance of non-physiological blood flow and minimization of the risk of complications related to inflammatory response. Inflammation plays a significant role in atherosclerosis progression and its complications [5,6].

One of the more easily accessible markers of inflammatory response is neutrophil-tolymphocyte ratio (NLR). Its capacity to predict adverse outcomes in patients with coronary artery disease has already been postulated [7].

The aim of the study was to compare postoperative results of NLR with mid-term OPCAB results, since there are no medical references evaluating the correlation between postoperative NLR and mid-term mortality risk in off-pump surgery. 


\section{Materials and Methods}

\subsection{Study Population}

In total, 224 patients (198 (88\%) men and $26(12 \%)$ women) with a mean age of $65 \pm 9$ years who had undergone OPCAB (off-pump coronary artery bypass grafting) through median full sternotomy at our Department in 2018 were enrolled into the study. Ethical approval was obtained from the local university's bioethics committee (273/21). All patients were provided with a form of written informed consent for a surgical procedure, and the research was conducted according to the principles laid down in the Declaration of Helsinki.

The presented group was subdivided in terms of 3-year survival into 2 subgroups. Detailed demographical and clinical information are presented in Table 1.

Table 1. Demographical and clinical data.

\begin{tabular}{|c|c|c|c|}
\hline Parameter & Group 1 Survivors $(n=198)$ & Group 2 Deceased $(n=26)$ & $p$-Value \\
\hline Gender M/F & $174(88 \%) / 25(12 \%)$ & $24(92 \%) / 2(8 \%)$ & $p=0.5483$ \\
\hline Age & $65+/-9$ & $67+/-9$ & $p=0.2869$ \\
\hline \multicolumn{4}{|l|}{ Concomitant diseases: } \\
\hline 1. arterial hypertension & $166(84 \%)$ & $21(81 \%)$ & $p=0.6973$ \\
\hline 2. $\mathrm{DM}$ & $78(39 \%)$ & $9(65 \%)$ & $p=0.0116$ \\
\hline 3. Stroke & $5(3 \%)$ & $8(31 \%)$ & $p<0.0001$ \\
\hline 4. Hypercholesterolemia & $134(68 \%)$ & $18(70 \%)$ & $p=0.8368$ \\
\hline 5. PAD & $29(15 \%)$ & $11(42 \%)$ & $p=0.0008$ \\
\hline \multicolumn{3}{|l|}{ Surgical indication: } & $p=0.5650$ \\
\hline 1. LM disease & $102(52 \%)$ & $12(46 \%)$ & $p=0.5629$ \\
\hline 2. 3 vessels disease & $88(44 \%)$ & $13(50 \%)$ & $p=1.0000$ \\
\hline 3. 2 vessels disease & $8(4 \%)$ & $1(4 \%)$ & \\
\hline \multicolumn{4}{|l|}{ Echocardiographic results } \\
\hline 1. LV diameter $(\mathrm{mm})$ & $47+/-6$ & $48+/-6$ & $p=0.4257$ \\
\hline 2. $\operatorname{LVEF}(\%)$ & $54+/-8$ & $50+/-7$ & $p=0.0159$ \\
\hline \multicolumn{4}{|l|}{ Surgery: } \\
\hline 1. overall time (min) & $141+/-42$ & $139+/-39$ & $p=0.8182$ \\
\hline 2. Mean anastomosis & $2.3+/-0.7$ & $2.3+/-0.7$ & $p=1.0000$ \\
\hline $\begin{array}{l}\text { Hospitalization time (days) } \\
\text { (excluding in hospital mortality) }\end{array}$ & $8.8+/-3$ & $\begin{array}{l}13+/-10 \\
(10+/-4)\end{array}$ & $p=0.0433$ \\
\hline
\end{tabular}

Abbreviations: COPD—chronic obstructive pulmonary disease, DM-diabetes mellitus, LV—left ventricle, LVEFleft ventricle ejection fraction, PAD—peripheral artery disease.

The mean follow-up time was 2.5 years. The data were collected from initial hospitalization, followed by regular checks at an outpatient clinic and telephone survey. The exclusion criteria included temporary mechanical support prior to surgery, including intraortic balloon counterpulsation, the need for respiratory support, kidney failure requiring hemodialysis, a previous cardiac surgery, an active infection, or an acute phase of myocardial infarction. Chronic inflammatory diseases and a history of oncological diseases were also added to the exclusion criteria.

\subsection{Patient and Public Partnership}

The patients were first enlisted into the study by verification of their survival, and their participation was voluntary, subject to being informed of the study. Survival was additionally assessed using national electronic verification data available for our country.

\subsection{Laboratory Analysis}

Laboratory results were obtained prior to surgery, as well as on day 1 and day 7 following the surgery. The perioperative laboratory results are presented in Table 2 . The whole blood count was the only standard laboratory test presenting inflammatory reaction on the 1st and 7th postoperative days. The other inflammatory parameters, such as Creactive protein (CRP) or procalcitonine, were assessed only if infection was suspected. 
Table 2. Perioperative laboratory results.

\begin{tabular}{|c|c|c|c|}
\hline Parameters & Group 1 Survivors $(n=198)$ & Group 2 Deceased $(n=26)$ & $p$-Value \\
\hline \multicolumn{4}{|l|}{ Preoperative: } \\
\hline 1. $\mathrm{WBC}, \times 10^{9} / \mathrm{L}($ mean $\pm \mathrm{SD})$ & $8.4+/-3.3$ & $7.7+/-1.9$ & $p=0.6780$ \\
\hline 2. Neutrophils, $\times 10^{9} / \mathrm{L}($ mean $\pm \mathrm{SD})$ & $5.3+/-1.7$ & $5.1+/-1.5$ & $p=0.7849$ \\
\hline 3. Lymphocyte, $\times 10^{9} / \mathrm{L}($ mean $\pm \mathrm{SD})$ & $2.2+/-2.5$ & $1.8+/-0.7$ & $p=0.4513$ \\
\hline 4. $\mathrm{Hb}, \mathrm{mmol} / \mathrm{L}($ mean $\pm \mathrm{SD})$ & $8.7+/-0.9$ & $8.6+/-1.1$ & $p=0.9893$ \\
\hline 5. Plt, $\times 10^{9} / \mathrm{L}($ mean $\pm \mathrm{SD})$ & $229+/-63$ & $233+/-63$ & $p=0.9397$ \\
\hline 6. $\quad$ NLR $($ mean $\pm S D)$ & $3.3+/-1.8$ & $3.2+/-1.5$ & $p=0.7119$ \\
\hline 7. Troponin, $\mathrm{ng} / \mathrm{mL}($ mean $\pm \mathrm{SD})$ & $0.23+/-2.8$ & $0.02+/-0.4$ & $p=0.1442$ \\
\hline \multicolumn{4}{|l|}{ Postoperative 1st day): } \\
\hline 1. WBC, $\times 10^{9} / \mathrm{L}($ mean $\pm \mathrm{SD})$ & $9.1+/-5$ & $12.1+/-13$ & $p=0.0331$ \\
\hline 2. Neutrophils, $\times 10^{9} / \mathrm{L}($ mean $\pm \mathrm{SD})$ & $5.2+/-2$ & $8.7+/-11$ & $p=0.0012$ \\
\hline 3. Lymphocyte, $\times 10^{9} / \mathrm{L}($ mean $\pm \mathrm{SD})$ & $2.5+/-3.4$ & $1.8+/-0.7$ & $p=0.0779$ \\
\hline 4. $\mathrm{Hb}, \mathrm{mmol} / \mathrm{L}($ mean $\pm \mathrm{SD})$ & $6.9+/-0.6$ & $7+/-0.5$ & $p=0.3570$ \\
\hline $\mathrm{Plt}, \times 10^{9} / \mathrm{L}($ mean $\pm \mathrm{SD})$ & $304+/-92$ & $354+/-107$ & $p=0.0157$ \\
\hline 6. NLR (mean $\pm \mathrm{SD})$ & $2.8+/-1.6$ & $5.1+/-3.6$ & $p=0.0003$ \\
\hline 7. Troponin, $\mathrm{ng} / \mathrm{mL}($ mean $\pm \mathrm{SD})$ & $4+/-6.3$ & $9.9+/-11$ & $p=0.1206$ \\
\hline \multicolumn{4}{|l|}{ Postoperative 7th day): } \\
\hline 1. WBC, $\times 10^{9} / \mathrm{L}($ mean $\pm \mathrm{SD})$ & $9.1+/-4.9$ & $9.2+/-2.6$ & $p=0.4047$ \\
\hline 2. Neutrophils, $\times 10^{9} / \mathrm{L}($ mean $\pm \mathrm{SD})$ & $5.1+/-1.9$ & $5.5+/-2.1$ & $p=0.3956$ \\
\hline 3. Lymphocyte, $\times 10^{9} / \mathrm{L}($ mean $\pm \mathrm{SD})$ & $2.5+/-3.4$ & $2.4+/-1.7$ & $p=0.4216$ \\
\hline 4. $\mathrm{Hb}, \mathrm{mmol} / \mathrm{L}($ mean $\pm \mathrm{SD})$ & $6.9+/-0.6$ & $7.1+/-0.7$ & $p=0.1483$ \\
\hline 5. Plt, $\times 10^{9} / \mathrm{L}($ mean $\pm \mathrm{SD})$ & $305.7+/-93.4$ & $283.5+/-70.6$ & $p=0.2592$ \\
\hline 6. NLR $($ mean $\pm \mathrm{SD})$ & $2.7+/-1.4$ & $3+/-1.9$ & $p=0.6694$ \\
\hline 7. Troponin, $\mathrm{ng} / \mathrm{mL}($ mean $\pm \mathrm{SD})$ & $0.2+/-1.0$ & $0.1+/-0.5$ & $p=0.7638$ \\
\hline
\end{tabular}

$\mathrm{Hb}$-hemoglobin, Me—mediana, NLR—neutrophil to lymphocyte ratio, Plt—platelets, Q—quartile, WBC—white blood count.

Postoperative mid-term results, including survival rate, clinical status, and the risk of major adverse events, were meticulously collected.

Postoperative myocardial infarction (type 5) diagnosis was based on the following criteria: elevated serum Troponin-I levels combined with a decrease in left ventricle ejection fraction in accordance with fourth universal definition [8].

\subsection{Surgical Technique}

Procedures were performed through median sternotomy without cardiopulmonary bypass application (OPCAB technique) by a team of experienced surgeons. Prior to performing anastomosis, heparin was administered according to the results of ACT (activating clotting time) with a mean value of $458 \pm 42 \mathrm{~s}$. The Octopus III (Medtronic, Minneapolis, $\mathrm{MN}, \mathrm{USA}$ ) local stabilizer was used in combination with a deep pericardial stitch to elevate the beating heart. Following the application of intraluminal shunts into coronary arteries, the anastomoses were performed with a monofilament 7-0 suture. A double dose of protamine was routinely administered after performing the anastomoses in order to reverse heparin action (mean ACT $132 \pm 36 \mathrm{~s}$ ).

\subsection{Clinical Endpoint}

To identify the effect of the post-procedural NLR on mid-term mortality in patients undergoing off-pump surgical revascularization.

\subsection{Statistical Analysis}

Continuous variables were reported as mean \pm standard deviation (SD). Categorical data were presented as numbers and percentages. The comparison of interval parameters between the survivors and the deceased group was performed by Student's t-test, and, if the data did not follow the normal distribution, the Mann-Whitney test was used as an alternative. Categorical data were analyzed using the test of proportions. The Cox's proportional hazard regression model was used to check whether the analyzed demographical and clinical data could be a risk factor for all-cause mortality. Both univariate and multivariate analyses were performed. Additionally, for significant factors, the ROC 
analysis was performed to find the optimal cut-off point for continuous parameters. In the next step, a multivariable Cox's model was used, wherein all data were binary. The analysis was performed using MedCalc ${ }^{\circledR}$ Statistical Software version 19.6 (MedCalc Software Ltd., Ostend, Belgium). All tests were considered significant at $p<0.05$.

\section{Results}

There were two (1\%) perioperative deaths and seven (3\%) myocardial infarctions in the presented groups. A three-year follow-up was not completed by 24 individuals, with a $10 \%$ mortality rate, and major adverse cardiovascular (MACE) events combined with percutaneous interventions were found in $12(5 \%)$ more patients.

There were 26 deaths in the presented analysis related to $15(58 \%)$ coronary syndromes and $11(42 \%)$ secondary to stroke.

The two groups (the deceased (non-survivors) and the survivors) were statistically different regarding concomitant diseases, including: history of stroke $(p<0.0001)$, peripheral artery disease $(p=0.0008)$, and left ventricle ejection fraction $(p=0.002)$.

The median values of the maximum Troponin-I serum level following the surgery were $4 \pm 6$ vs. $9.9 \pm 11 \mathrm{mcg} / \mathrm{L}$ in groups 1 and 2, respectively. Detailed results are presented in Table 2.

The preoperative NLR results were comparable in both groups ( $3.3 \pm 1.8$ vs. $3.2 \pm 1.5$ $(p=0.7119)$ in the survivors vs. the deceased group, respectively). A postoperative NLR increase on post-op day 1 was observed in the survivors and the deceased group ( $2.8 \pm 1.6$ vs. $5.1 \pm 3.6(p=0.0003)$ and $2.7 \pm 1.4$ vs. $3 \pm 1.9(p=0.6694)$, respectively). The NLR increase on post-op day 1 decreased back to preoperative values on day 7 . The preoperative NLR and its values on post-op day 7 in the survivors group was lower $(3.3 \pm+/-1.8$ vs. $2.7 \pm 1.4(p=0.0002)$ and comparable in the deceased group, $3.2 \pm 1.5$ vs. $3 \pm 1.9$ $(p=0.6754)$.

Interestingly, the maximal serum levels of myocardial injury markers (Troponin-I) were comparable between both groups $(4 \pm 6.3 \mathrm{mcg} / \mathrm{L}$ and $9.9 \pm 11 \mathrm{mcg} / \mathrm{L}(p=0.1206))$. Preoperative and postoperative whole blood count data, including the commonly accepted marker of inflammatory reaction, such as neutrophil-to-lymphocyte ratio (NLR), are presented in Table 2.

Univariable and multivariable Cox's proportional hazard regression analysis was performed and is presented in Table 3.

Table 3. Univariable and multivariable Cox's proportional hazard regression analysis.

\begin{tabular}{|c|c|c|c|c|c|c|}
\hline \multirow[b]{2}{*}{ Parameter } & \multicolumn{3}{|c|}{ Univariate Analysis } & \multicolumn{3}{|c|}{ Multivariate Analysis } \\
\hline & HR & $95 \% \mathrm{CI}$ & $p$-Value & HR & $95 \% \mathrm{CI}$ & $p$-Value \\
\hline Gender M/F Ref. =F & 2.55 & $0.60-10.79$ & 0.2034 & & & \\
\hline Age & 1.03 & $0.97-1.07$ & 0.2823 & & & \\
\hline \multicolumn{7}{|l|}{ Concomitant diseases: } \\
\hline Arterial hypertension & 1.32 & $0.49-3.51$ & 0.5736 & & & \\
\hline $\mathrm{DM}$ & 0.98 & $0.43-2.23$ & 0.9668 & & & \\
\hline Stroke & 14.07 & $6.34-31.22$ & $<0.0001$ & & & \\
\hline Hypercholesterolemia & 1.35 & $0.59-3.11$ & 0.4752 & & & \\
\hline PAD & 3.9 & $1.77-8.60$ & 0.0007 & & & \\
\hline \multicolumn{7}{|l|}{ Surgical indication: } \\
\hline LM disease & 0.85 & $0.39-1.85$ & 0.6906 & & & \\
\hline 3 vessels disease & 1.14 & $0.52-2.50$ & 0.7314 & & & \\
\hline 2 vessels disease & 1.74 & $0.80-3.81$ & 0.1597 & & & \\
\hline
\end{tabular}


Table 3. Cont.

\begin{tabular}{|c|c|c|c|c|c|c|}
\hline \multirow[b]{2}{*}{ Parameter } & \multicolumn{3}{|c|}{ Univariate Analysis } & \multicolumn{3}{|c|}{ Multivariate Analysis } \\
\hline & HR & $95 \% \mathrm{CI}$ & $p$-Value & HR & $95 \% \mathrm{CI}$ & $p$-Value \\
\hline \multicolumn{7}{|c|}{ Echocardiographic results: } \\
\hline LV diameter $(\mathrm{mm})$ & 1.08 & $1.02-1.16$ & 0.0191 & & & \\
\hline LVEF (\%) & 0.88 & $0.85-0.91$ & $<0.0001$ & 0.92 & $0.87-0.95$ & $<0.0001$ \\
\hline \multicolumn{7}{|l|}{$\begin{array}{l}\text { Preoperative: } \\
(\text { mean } \pm \text { SD) }\end{array}$} \\
\hline $\mathrm{WBC}, \times 10^{9} / \mathrm{L}$ & 0.92 & $0.77-1.09$ & 0.3248 & & & \\
\hline Neutrophils, $\times 10^{9} / \mathrm{L}$ & 0.94 & $0.75-1.19$ & 0.6364 & & & \\
\hline Lymphocyte, $\times 10^{9} / \mathrm{L}$ & 0.78 & $0.45-1.35$ & 0.3734 & & & \\
\hline $\mathrm{Hb}, \mathrm{mmol} / \mathrm{L}$ & 0.98 & $0.62-1.52$ & 0.9218 & & & \\
\hline Plt, $\times 10^{9} / \mathrm{L}$ & 1 & $0.99-1.01$ & 0.7882 & & & \\
\hline NLR & 1.04 & $0.84-1.29$ & 0.6986 & & & \\
\hline Troponin, ng/mL & 0.91 & $0.34-2.41$ & 0.8498 & & & \\
\hline \multicolumn{7}{|l|}{$\begin{array}{l}\text { Postoperative 1st day: } \\
(\text { mean } \pm \text { SD) }\end{array}$} \\
\hline WBC, $\times 10^{9} / \mathrm{L}$ & 1.05 & $1.01-1.08$ & 0.0059 & 1.18 & $1.07-1.30$ & 0.0006 \\
\hline Neutrophils, $\times 10^{9} / \mathrm{L}$ & 1.59 & $1.33-1.89$ & $<0.0001$ & 0.36 & $0.22-0.58$ & $<0.0001$ \\
\hline Lymphocyte, $\times 10^{9} / \mathrm{L}$ & 0.64 & $0.37-1.10$ & 0.1047 & & & \\
\hline $\mathrm{Hb}, \mathrm{mmol} / \mathrm{L}$ & 1.14 & $0.61-2.15$ & 0.6848 & & & \\
\hline Plt, $\times 10^{9} / \mathrm{L}$ & 1.01 & $1.01-1.01$ & 0.0065 & 1.01 & $1.01-1.01$ & 0.0038 \\
\hline NLR & 1.47 & $1.30-1.65$ & $<0.0001$ & 1.61 & $1.18-2.18$ & 0.0022 \\
\hline Troponin, ng/mL & 0.99 & $0.99-1.01$ & 0.8088 & & & \\
\hline \multicolumn{7}{|l|}{ Postoperative 7 th day: } \\
\hline $\mathrm{WBC}, \times 10^{9} / \mathrm{L}$ & 1.11 & $0.93-1.32$ & 0.2687 & & & \\
\hline Neutrophils, $\times 10^{9} / \mathrm{L}$ & 0.99 & $0.87-1.12$ & 0.8528 & & & \\
\hline Lymphocyte, $\times 10^{9} / \mathrm{L}$ & 1.53 & $0.85-2.74$ & 0.1524 & & & \\
\hline $\mathrm{Hb}, \mathrm{mmol} / \mathrm{L}$ & 0.98 & $0.99-1.01$ & 0.3514 & & & \\
\hline Plt, $\times 10^{9} / \mathrm{L}$ & 1.1 & $0.88-1.38$ & 0.412 & & & \\
\hline NLR & 0.94 & $0.56-1.57$ & 0.8105 & & & \\
\hline Troponin, ng/mL & & & & & & \\
\hline
\end{tabular}

Abbreviations: $\mathrm{F}$-female, $\mathrm{DM}$-diabetes mellitus, $\mathrm{Hb}$-hemoglobin, $\mathrm{LV}-$ left ventricle, LVEF—left ventricle ejection fraction, $\mathrm{M}-\mathrm{male}$ NLR —neutrophil to lymphocyte ratio, PAD—peripheral artery disease, Plt—platelets.

In the univariable analysis, stroke in medical history (HR 14.07, 6.34-31.22, 95\%CI, $p<$ 0.0001 ) and peripheral artery disease (HR 3.9, 1.77-8.6 95\% CI, $p=0.0007$ ) were found to be significant demographical factors affecting survival. Postoperative echocardiographic results, including left ventricle diastolic dimension (HR 1.08, 1.02-1.16, 95\% CI, $p=0.0191$ ) and ejection fraction (HR $0.88,0.85-0.91,95 \% \mathrm{CI}, p<0.0001$ ). Interestingly, among the laboratory parameters, those measured on post-op day 1 were statistically significantly predictive of survival, including neutrophils (HR 1.59, 1.33-1.89 95\%CI, $p<0.0001$ ), platelets (HR 1.01, 1.01-1.01 95\%CI, $p=0.0065)$, and NLR (HR 1.47, 1.3-1.65 95\%CI, $p<0.0001$ ).

NLR above 4.6 was found to be related to mid-term survival as presented in Figure 1. 


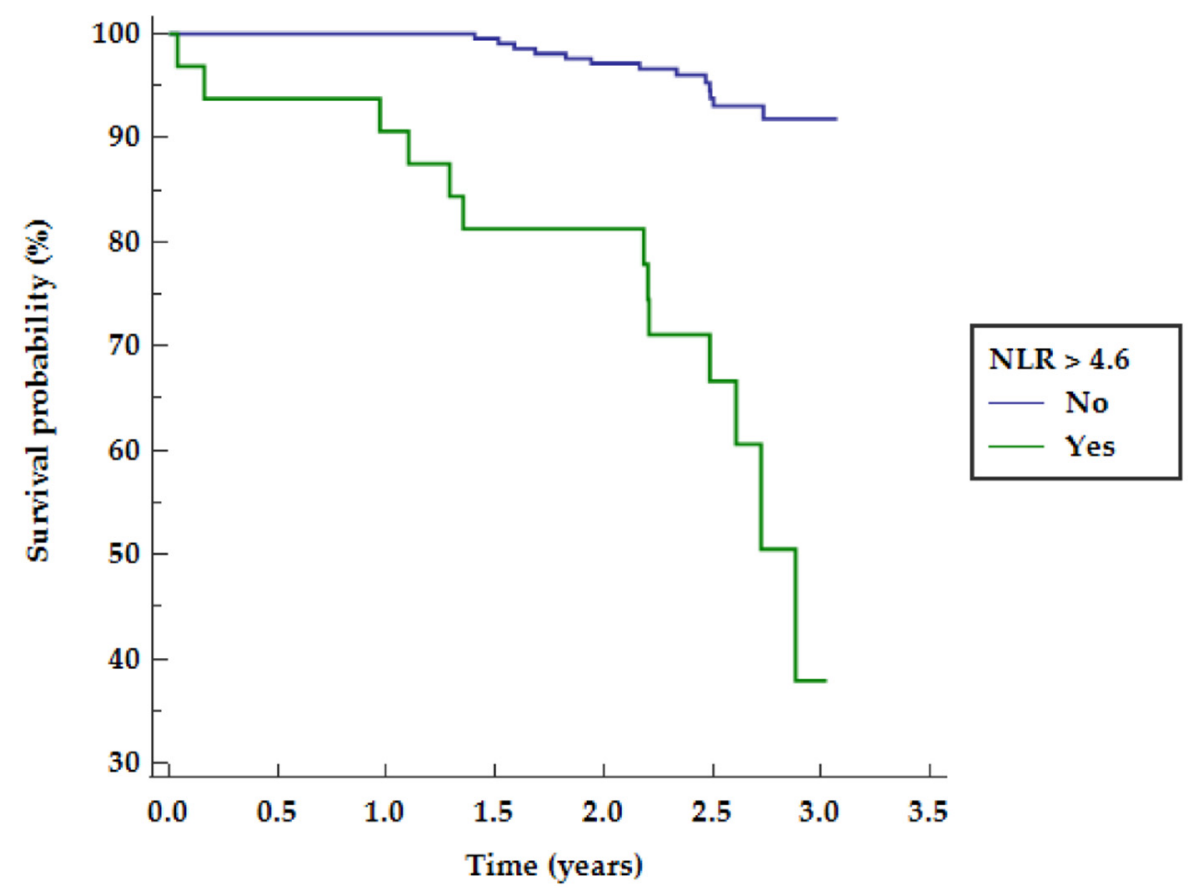

Figure 1. NLR probability of mid-term survival. NLR—neutrophil to lymphocyte ratio.

Postoperative ejection fraction (HR $0.9,0.87-0.9595 \% \mathrm{CI}, p<0.0001$ ) and laboratory parameters noted on post-op day 1 were found to represent significant factors in the multivariable analysis (Table 3).

Receiver operating characteristic curves for Cox's model revealed the following significant parameters: $\mathrm{LVEF} \leq 50 \%$ with AUC $=0.892$ (sensitivity $88.6 \%$ and specificity $76 \%$ ), WBC above 7.6 10E9/L with AUC $=0.628$ (sensitivity $88.5 \%$ and specificity $38 \%$ ), Plt above $350 \mathrm{k} / \mathrm{L}$ with AUC $=0.645$ (sensitivity $54 \%$ and specificity $76 \%$ ), and NLR above 4.6 with AUC $=0.715$ (sensitivity $50 \%$ and specificity 91\%) (Figure 2).

The multivariable Cox's proportional hazard regression analysis was performed once again, taking all significant parameters as a binary. The results were presented in Table 4 , including left ventricle ejection fraction $\leq 50 \%$ (HR 12.6, 3.69-42.72 95\%CI, $p=0.0001$ ), WBC > 7.6 (HR 1.04, 0.32-3.45 95\%CI, $p=0.9409$ ), platelets $>350 \mathrm{k} / \mathrm{L}$ (HR 2.7, 1.19-6.15 $95 \% \mathrm{CI}, p=0.018)$ and NLR $>4.6$ (HR 9.3, 3.6-24.02 95\%CI, $p<0.0001)$. 

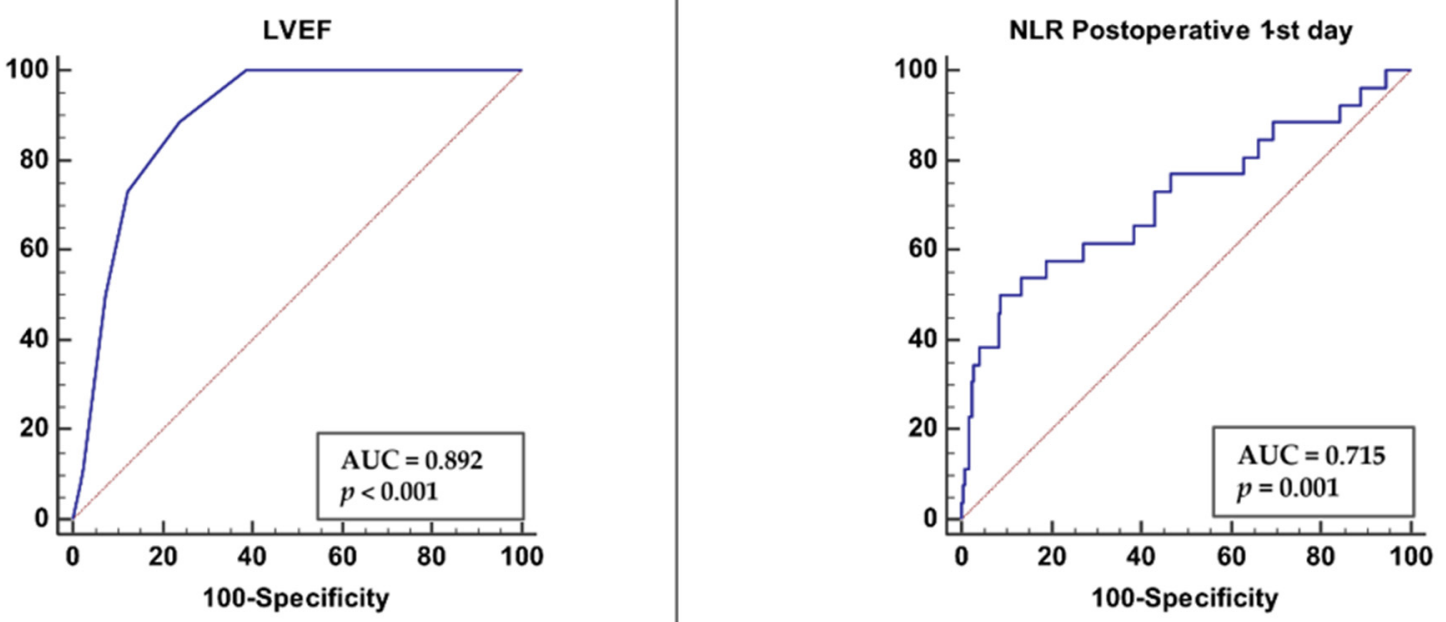

\section{A. LVEF}

Cut-off point: $\mathbf{L V E F}<=\mathbf{5 0}$

Sensitivity $88.56 \%$; Specificity $75.90 \%$

\section{Cut-off point: NLR $>$ 4.6}

Sensitivity $50.00 \%$; Specificity $91.20 \%$
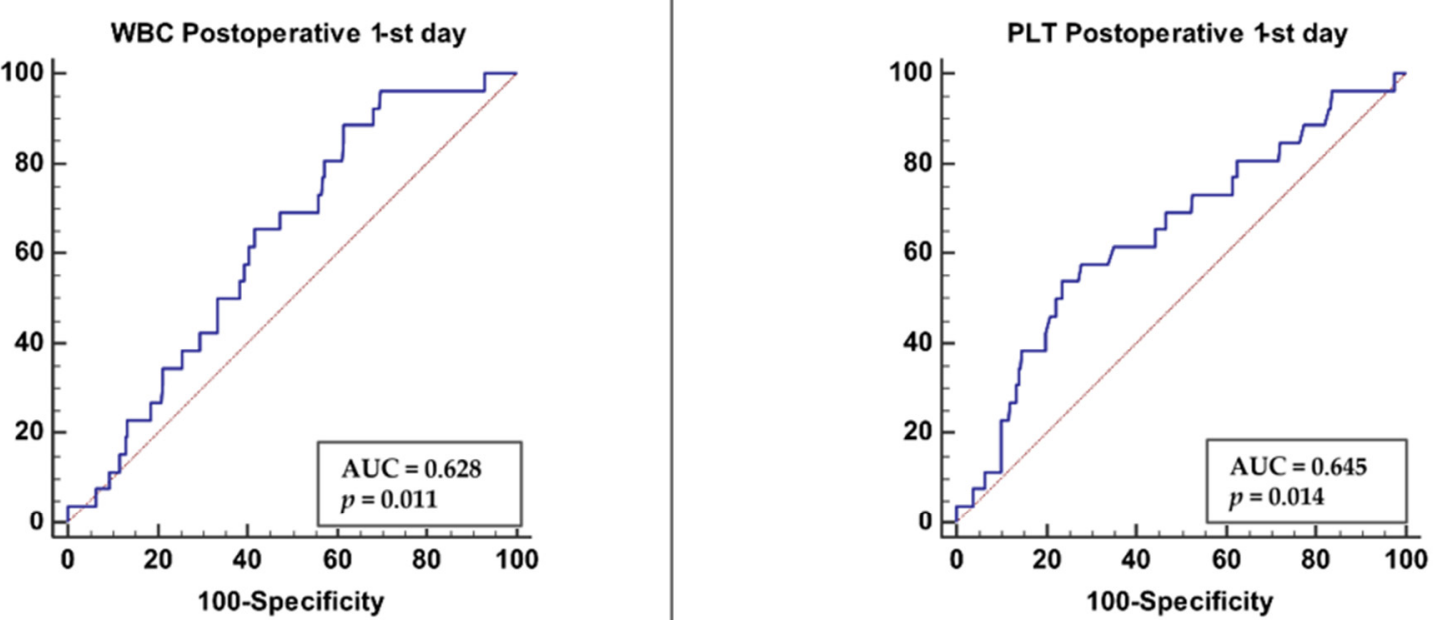

C. WBC Postoperative 1-st day

Cut-off point: WBC 1-st day $>$ 7.6

Sensitivity $88.46 \%$; Specificity $38.43 \%$

\section{PLT Postoperative 1-st day}

Cut-off point: PLT 1-st day > 350

Sensitivity $53.85 \%$; Specificity $76.39 \%$

Figure 2. Receiver operating characteristic curves for Cox's model LVEF (A). NLR on first postoperative day (B). WBC on first postoperative day (C). PLT on first postoperative day (D). Abbreviations: LVEF-left ventricle ejection fraction, NLR—neutrophil to lymphocyte ratio, PLT—platelets count, WBC—white blood count.

Table 4. Multivariable Cox's proportional hazard regression analysis—binary covariates.

\begin{tabular}{|c|c|c|c|}
\hline Parameter & HR & $95 \% \mathrm{CI}$ & $p$-Value \\
\hline $\mathrm{LVEF} \leq 50$ & 12.56 & $3.69-42.72$ & 0.0001 \\
\hline WBC $>7.6$ & 1.04 & $0.32-3.45$ & 0.9409 \\
\hline Plt $>350$ & 2.70 & $1.19-6.15$ & 0.0180 \\
\hline NLR > 4.6 & 9.30 & $3.60-24.02$ & $<0.0001$ \\
\hline
\end{tabular}

Abbreviations: LVEF-left ventricle ejection fraction, NLR—neutrophil to lymphocyte ratio, PLT—platelets, WBC—white blood count. 


\section{Discussion}

The unique result of the study is the relationship between the NLR increase on the first postoperative days after off-pump surgical revascularization and mid-term survival in multivariable analysis. In our analysis, four parameters were found to be related to mid-term mortality, including postoperative ejection fraction below $50 \%$, NLR above 4.6, WBC above 7.6, and platelet count above $350 \mathrm{k}$ per liter. The strongest predictor for mid-term survival was left ventricle ejection fraction (AUC $=0.895$ ). The results of our study present the NLR as an independent mortality predictor following the OPCAB procedure with moderate significance $(A U C=0.715)$. This study points out the significance of inflammatory reaction activation as one of the possible prognostic factors.

Surgical stress by cellular immunity suppression may result in postoperative systemic leukocytic alterations, including leukocytosis, neutrophilia, lymphopenias, or inflammatory mediator overproduction [9].

The high NLR (above 4.6) on post-op day 1 was positively correlated with 3-year mortality. The results indicate that inflammatory processes occurring one day after the surgery have a significant negative impact on the patient's survival. The postoperative NLR results were related to ICU stay and length of hospitalization in previous studies [10]. The correlation between the risk of MACCE following surgical revascularization in CPB was presented with a cut-off value of 4.32 in the multivariable analysis [11]. We present the results of the study with a similar cut-off value for mid-term mortality as the endpoint analysis. We would like to point out that NLR reverted to preoperative values on post-op day 7 . This suggests that after a surgical procedure, inflammatory processes are temporarily activated, and may trigger an unknown cascade leading to increased mortality within 2.5 years' time. The overactivation of inflammatory system was transient, but further investigation seems to be required to distinguish between the prevalence of the patients' hyperreactivity and a single inducible reaction. The association between increased preoperative NLR and cardiovascular risk, as well as cardiovascular and cerebrovascular events (MACE), in the 30-day postoperative period in non-cardiac surgery was presented by Larman [12].

Tan in his review postulated the association of increased preoperative values of NLR ( $>3.3$ in cardiac surgery) with increased mortality at a mean follow-up of 34.8 months [13].

Increased NLR represents neutrophil activation combined with lymphocyte depletion. Neutrophils, as short-lived phagocytic cells, are characterized by a broad spectrum of biologically active molecules (myeloperoxidase, proteinases) [14]. According to Zernecke, the increased neutrophil content in plaques is associated with apoptosis and a proinflammatory phenotype [15]. In his study, the activation of circulating neutrophils was investigated, as labeled neutrophils were noted in atherosclerotic plaques after 8 weeks.

Myocardial ischemia/reperfusion injury occurring in the early postoperative phase involves the activation of neutrophils (and other cellular blood elements) combined with complementary system activation and molecular oxygen [16]. Lymphopenia, as observed in high NLR values, is another independent factor for atherosclerosis progression, as presented in previous studies $[17,18]$.

The results of our study found a statistically significant relationship between WBC and survival in multivariable analysis. There are other studies in the literature presenting total white blood cell count (WBC) as a mortality predictor after surgical revascularization [19]. Other variables in outcome prediction include subtypes of WBC or specific ratios, such as the neutrophil-to-lymphocyte ratio [20]. If the whole blood count parameters are easily affected by the patient's hydration level, NLR is believed to be relatively stable.

Contrarily, the Troponin-I serum level, a commonly used marker for myocardial injury, was not found in our results to be a mid-term mortality risk factor. This corroborates with the results obtained by Yan Li [21].

We present the relationship between perioperative NLR ratio and 3-year survival as the perioperative indicator of inflammatory response to the procedure. Chronic inflammatory processes are linked to atherosclerosis progression and plaque rupture, as presented in 
the review by Yuhua Zhu [22]. Inflammation initiates and promotes the development of atherosclerotic changes. We believe that the increased inflammatory activation during the perioperative period may strongly affect results, since surgical injury induces endogenous mediators that alter the immuno-inflammatory response [23].

Avoiding cardiopulmonary bypass during surgical revascularization has been proven to limit inflammatory response $[24,25]$. Contrarily, the complementary cascade of activation was on a similar level, according to Ascione's study [26]. Additionally, neurohumoral activation triggering the systemic stress response was presented in a prospective study by Velissaris [27]. Shulze revealed the significantly lower expression of the TNF-system and Il-2r in OPCAB patients compared to CBP, except for similar Il-6 levels [28].

Postoperative high serum levels of C-reactive protein-another inflammatory marker commonly used in clinical practice-were found by Min [29] to be associated with a risk of MACE in the long-term.

Our study results present a negative correlation between left ventricle ejection fraction and mid-term survival. Decreased LVEF levels below $50 \%$ were found to be a mortality predictor. Postoperative deterioration of the left ventricle ejection fraction represents a myocardial perioperative injury significantly related to long-term survival, as postulated in previous studies [30,31].

The results from our retrospective analysis present the link between inflammatory reaction activation and risk for mid-term mortality. The NLR was found be a marker of moderate significance in the presented study. The significance of NLR in the perioperative period of cardiovascular procedures was already presented [32]. Nevertheless, the deaths were related to cardiovascular complications with known linkages to inflammatory processes [22].

We present a statistically significant relationship between the platelet count and mortality risk. Increased platelet counts are closely related to inflammatory reactions and increased NLR [33]. Contact between platelets and neutrophils modulates the thrombotic and inflammatory reaction [34]. High NLR may also increase platelet activity in the patient after coronary artery interventions, and both combined may help identify the patients with high risk of recurrent acute syndrome $[35,36]$. Therefore, we believe that the close relationship between platelets and NLR indicate that one of them should be considered a predictor.

This was a retrospective study, but it highlights possible new approaches to patients undergoing $\mathrm{OPCAB}$ procedures. We intend to follow up more closely this group of patients (NLR > 4.6) with more frequent tests, including treadmill tests and angiographies, if indicated. This group will be more closely monitored regarding cardiovascular risk factors, including hypertension.

\section{Conclusions}

Postoperative increases in NLR, as an inflammatory reaction marker, are related to mid-term mortality in OPCAB patients.

Author Contributions: Conceptualization, T.U., M.M., B.P. and M.J.; methodology, T.U., M.M., A.G. and B.P.; software, T.U., M.R. and M.B.; validation, M.M.; formal analysis, M.M.; investigation, T.U., A.G., M.R. and M.B.; resources, T.U., A.G., M.R. and M.B.; data curation, T.U., A.G., M.R. and M.B.; writing—original draft preparation, T.U., M.M., A.G. and B.P.; writing—review and editing, E.S.-M. and M.J.; supervision, B.P., E.S.-M. and M.J.; project administration, T.U; funding acquisition, M.J. All authors have read and agreed to the published version of the manuscript.

Funding: This research received no external funding.

Institutional Review Board Statement: The study was conducted according to the guidelines of the Declaration of Helsinki and approved by the Ethics Committee) of Poznan University of Medical Sciences (protocol code 55/20, 16th January 2020-date of approval).

Informed Consent Statement: Informed consent for surgery was obtained from all subjects involved in the study as standard procedure. The study is a retrospective analysis. 
Data Availability Statement: All data will be available under the correspondence e-mail address for 3 years following the publication after justifiable request.

Conflicts of Interest: The authors declare no conflict of interest.

\section{References}

1. Bronicki, R.A.; Hall, M. Cardiopulmonary Bypass-Induced Inflammatory Response: Pathophysiology and Treatment. Pediatr. Crit. Care Med. 2016, 17, S272-S278. [CrossRef] [PubMed]

2. Kuwahara, G.; Tashiro, T. Current Status of Off-Pump Coronary Artery Bypass. Ann. Thorac. Cardiovasc. Surg. 2020, 26, 125-132. [CrossRef]

3. Chivasso, P.; Guida, G.A.; Fudulu, D.; Bruno, V.D.; Marsico, R.; Sedmakov, H.; Zakkar, M.; Rapetto, F.; Bryan, A.J.; Angelini, G.D. Impact of off-pump coronary artery bypass grafting on survival: Current best available evidence. J. Thorac. Dis. 2016, 8, 808-817. [CrossRef]

4. Puskas, J.D.; Williams, W.H.; Mahoney, E.M.; Huber, P.R.; Block, P.C.; Duke, P.G.; Staples, J.R.; Glas, K.E.; Marshall, J.J.; Leimbach, M.E.; et al. Off-pump vs conventional coronary artery bypass grafting: Early and 1-year graft patency, cost, and quality-of-life outcomes: A randomized trial. JAMA 2004, 291, 1841-1849. [CrossRef]

5. Wirtz, P.H.; von Känel, R. Psychological Stress, Inflammation, and Coronary Heart Disease. Curr. Cardiol. Rep. 2017, 19, 111-117. [CrossRef] [PubMed]

6. Sawant, A.C.; Adhikari, P.; Narra, S.R.; Srivatsa, S.S.; Mills, P.K.; Srivatsa, S.S. Neutrophil to lymphocyte ratio predicts shortand long-term mortality following revascularization therapy for ST elevation myocardial infarction. Cardiol. J. 2014, 21, 500-508. [CrossRef]

7. Azab, B.; Zaher, M.; Weiserbs, K.F.; Torbey, E.; Lacossiere, K.; Gaddam, S.; Gobunsuy, R.; Jadonath, S.; Baldari, D.; McCord, D.; et al. Usefulness of neutrophil to lymphocyte ratio in predicting short- and long-term mortality after non-ST-elevation myocardial infarction. Am. J. Cardiol. 2010, 106, 470-476. [CrossRef]

8. Thygesen, K.; Alpert, J.S.; Jaffe, A.S.; Chaitman, B.R.; Bax, J.J.; Morrow, D.A.; White, H.D. The Executive Group on behalf of the Joint European Society of Cardiology (ESC)/American College of Cardiology (ACC)/American Heart Association (AHA)/World Heart Federation (WHF) Task Force for the Universal Definition of Myocardial Infarction. Fourth universal definition of myocardial infarction (2018). Circulation 2018, 138, e618-e651. [PubMed]

9. Kim, W.H.; Jin, H.S.; Ko, J.S.; Hahm, T.S.; Lee, S.M.; Cho, H.S.; Kim, M.H. The effect of anesthetic techniques on neutrophil-tolymphocyte ratio after laparoscopy-assisted vaginal hysterectomy. Acta Anaesthesiol. Taiwanica 2011, 49, 83-87. [CrossRef]

10. Özer, A.; Mardin, B.; Kılıç, Y.; Oktar, L.; İriz, E.; Arslan, M.; Ünal, Y.; Alkan, M. The effect of neutrophil-lymphocyte ratio on the postoperative course of coronary artery bypass graft surgery. Turk. J. Med. Sci. 2018, 48, 1036-1040. [CrossRef] [PubMed]

11. Gurbuz, O.; Kumtepe, G.; Ozkan, H.; Karal, I.H.; Velioglu, Y.; Ercan, A.; Yüksel, A.; Ener, S. Predictive Value of NeutrophilLymphocyte Ratio for Long-Term Cardiovascular Event Following Coronary Artery Bypass Grafting. Braz. J. Cardiovasc. Surg. 2020, 35, 274-284. [CrossRef] [PubMed]

12. Larmann, J.; Handke, J.; Scholz, A.S.; Dehne, S.; Arens, C.; Gillmann, H.J.; Uhle, F.; Motsch, J.; Weigand, M.A.; Janssen, H. Preoperative neutrophil to lymphocyte ratio and platelet to lymphocyte ratio are associated with major adverse cardiovascular and cerebrovascular events in coronary heart disease patients undergoing non-cardiac surgery. BMC Cardiovasc. Disord. 2020, 20, 230. [CrossRef] [PubMed]

13. Tan, T.P.; Arekapudi, A.; Metha, J.; Prasad, A.; Venkatraghavan, L. Neutrophil-lymphocyte ratio as predictor of mortality and morbidity in cardiovascular surgery: A systematic review. ANZ J. Surg. 2015, 85, 414-419. [CrossRef] [PubMed]

14. Galkina, E.; Ley, K. Immune and inflammatory mechanisms of atherosclerosis (*). Annu. Rev. Immunol. 2009, 27, 165-197. [CrossRef]

15. Zernecke, A.; Bot, I.; Djalali-Talab, Y.; Shagdarsuren, E.; Bidzhekov, K.; Meiler, S.; Krohn, R.; Schober, A.; Sperandio, M.; Soehnlein, O.; et al. Protective role of CXC receptor 4/CXC ligand 12 unveils the importance of neutrophils in atherosclerosis. Circ. Res. 2008, 102, 209-217. [CrossRef]

16. Chakraborti, T.; Mandal, A.; Mandal, M.; Das, S.; Chakraborti, S. Complement activation in heart diseases: Role of oxidants. Cell Signal. 2000, 12, 607-617. [CrossRef]

17. Huang, Y.L.; Chung, H.T.; Chang, C.J.; Yeh, K.W.; Chen, L.C.; Huang, J.L. Lymphopenia is a risk factor in the progression of carotid intima-media thickness in juvenile-onset systemic lupus erythematosus. Arthritis Rheum. 2009, 60, 3766-3775. [CrossRef] [PubMed]

18. Ducloux, D.; Challier, B.; Saas, P. CD4 cell lymphopenia and atherosclerosis in renal transplant recipients. J. Am. Soc. Nephrol. 2003, 14, 767-772. [CrossRef]

19. Bagger, J.P.; Zindrou, D.; Taylor, K.M. Leukocyte count: A risk factor for coronary artery bypass graft mortality. Am. J. Med. 2003, 115, 660-663. [CrossRef]

20. Horne, B.D.; Anderson, J.L.; John, J.M.; Weaver, A.; Bair, T.L.; Jensen, K.R.; Renlund, D.G.; Muhlestein, J.B. Intermountain Heart Collaborative Study Group. Which white blood cell subtypes predict increased cardiovascular risk? J. Am. Coll. Cardiol. 2005, 45, 1638-1643. [CrossRef] 
21. Li, Y.; Li, Y.; Hu, Q.; Zheng, S.; Tian, B.; Meng, F.; Chen, Z.; Han, J.; Wang, S.; Zhang, H.; et al. Association of early elevated cardiac troponin I concentration and longitudinal change after off-pump coronary artery bypass grafting and adverse events: A prospective cohort study. J. Thorac. Dis. 2020, 12, 6542-6551.

22. Zhu, Y.; Xian, X.; Wang, Z.; Bi, Y.; Chen, Q.; Han, X.; Tang, D.; Chen, R. Research Progress on the Relationship between Atheroscler. Inflamm. Biomol. 2018, 8, 80-91.

23. Hsi, C.H.-H.; Wang, J.J. Clinical implication of perioperative inflammatory cytokine alteration. Acta Anaesthesiol. Taiwanica 2015, 15, 23-28.

24. Raja, S.G.; Berg, G.A. Impact of off-pump coronary artery bypass surgery on systemic inflammation: Current best available evidence. J. Card. Surg. 2007, 5, 445-455. [CrossRef] [PubMed]

25. Al-Ruzzeh, S.; Hoare, G.; Marczin, N.; Asimakopoulos, G.; George, S.; Taylor, K.; Amrani, M. Off-pump coronary artery bypass surgery is associated with reduced neutrophil activation as measured by the expression of CD11b: A prospective randomized study. Heart Surg. Forum. 2003, 6, 89-93. [CrossRef] [PubMed]

26. Ascione, R.; Lloyd, C.T.; Underwood, M.J.; Lotto, A.A.; Pitsis, A.A.; Angelini, G.D. Inflammatory response after coronary revascularization with or without cardiopulmonary bypass. Ann. Thorac. Surg. 2000, 69, 1198-1204. [CrossRef]

27. Velissaris, T.; Tang, A.T.; Murray, M.; Mehta, R.L.; Wood, P.J.; Hett, D.A.; Ohri, S.K. A prospective randomized study to evaluate stress response during beating-heart and conventional coronary revascularization. Ann. Thorac. Surg. 2004, 78, 506-512. [CrossRef]

28. Stoppe, C.; Werker, T.; Rossaint, R.; Dollo, F.; Lue, H.; Wonisch, W.; Menon, A.; Goetzenich, A.; Bruells, C.S.; Coburn, M.; et al. What is the significance of perioperative release of macrophage migration inhibitory factor in cardiac surgery? Antioxid. Redox Signal. 2013, 19, 231-239. [CrossRef]

29. Min, J.J.; Nam, K.; Kim, T.K.; Kim, H.J.; Seo, J.H.; Hwang, H.Y.; Kim, K.B.; Murkin, J.M.; Hong, D.M.; Jeon, Y. Relationship between early postoperative $\mathrm{C}$-reactive protein elevation and long-term postoperative major adverse cardiovascular and cerebral events in patients undergoing off-pump coronary artery bypass graft surgery: A retrospective study. Br. J. Anaesth. 2014, 113, 391-401. [CrossRef] [PubMed]

30. Awan, N.I.; Jan, A.; Rehman, M.U.; Ayaz, N. The effect of ejection fraction on mortality in Coronary Artery Bypass Grafting (CABG) patients. Pak. J. Med. Sci. 2020, 36, 1454-1459. [CrossRef]

31. Popovic, B.; Agrinier, N.; Voilliot, D.; Voilliot, D.; Elfarra, M.; Villemot, J.P.; Maureira, P. Ventricular Dysfunction in Patients with Acute Coronary Syndrome Undergoing Coronary Surgical Revascularization: Prognostic Impact on Long-Term Outcomes. PLoS ONE 2016, 11, e0168634. [CrossRef]

32. Serra, R.; Ielapi, N.; Licastro, N.; Provenzano, M.; Andreucci, M.; Bracale, U.M.; Jiritano, F.; de Franciscis, S.; Mastroroberto, P.; Serraino, G.F. Neutrophil-to-lymphocyte Ratio and Platelet-to-lymphocyte Ratio as Biomarkers for Cardiovascular Surgery Procedures: A Literature Review. Rev. Recent Clin. Trials. 2021, 16, 173-179. [CrossRef]

33. Gasparyan, A.Y.; Ayvazyan, L.; Mukanova, U.; Yessirkepov, M.; Kitas, G.D. The Platelet-to-Lymphocyte Ratio as an Inflammatory Marker in Rheumatic Diseases. Ann. Lab. Med. 2019, 39, 345-357. [CrossRef] [PubMed]

34. Lako, S.; Dedej, T.; Nurka, T.; Ostreni, V.; Demiraj, A.; Xhaxho, R.; Prifti, E. Hematological Changes in Patients Undergoing Coronary Artery Bypass Surgery: A Prospective Study. Med. Arch. 2015, 69, 181-186. [CrossRef] [PubMed]

35. Verdoia, M.; Nardin, M.; Gioscia, R.; Negro, F.; Marcolongo, M.; Suryapranata, H.; Kedhi, E.; De Luca, G. Novara Atherosclerosis Study Group (NAS). Higher neutrophil-to-lymphocyte ratio (NLR) increases the risk of suboptimal platelet inhibition and major cardiovascular ischemic events among ACS patients receiving dual antiplatelet therapy with ticagrelor. Vascul. Pharmacol. 2020, 132, 106765. [CrossRef] [PubMed]

36. Adatia, K.; Farag, M.F.; Gue, Y.X.; Srinivasan, M.; Gorog, D.A. Relationship of Platelet Reactivity and Inflammatory Markers to Recurrent Adverse Events in Patients with ST-Elevation Myocardial Infarction. Thromb. Haemost. 2019, 119, 1785-1794. [CrossRef] 